\title{
Fishers weigh in: benefits and risks of eating Great Lakes fish from the consumer's perspective
}

\author{
Jennifer Dawson · Judy Sheeshka - Donald C. Cole • \\ David Kraft · Amy Waugh
}

Accepted: 11 October 2007/Published online: 5 March 2008

(C) Springer Science+Business Media B.V. 2008

\begin{abstract}
Three decades of concern over consumption of potentially contaminated Great Lakes fish has led government agencies and public health proponents to implement risk assessment and management programs as a means of protecting the health of fishers and their families. While well-meaning in their intent, these programs-and much of the research conducted to support and evaluate themwere not designed to accommodate the understandings and concerns of the fish consumer. Results from a qualitative component of a multi-disciplinary, multi-year research project on frequent (average 108 meals per year) consumers of Great Lakes fish tell the fishers' side of the story. We present data from 87 tape recorded interviews conducted with Vietnamese, Chinese, and English-speaking participants that underscore the quality of freshly caught Great Lakes fish and the important social and cultural benefits of fish and fishing to the consumer. We also outline the participants' understandings of risk from eating Great Lakes fish and the way in which fishers and their families
\end{abstract}

\section{J. Dawson}

McMaster Institute of Environment and Health, McMaster

University, Hamilton, ON, Canada

J. Sheeshka $(\square)$

Department of Family Relations \& Applied Nutrition, University

of Guelph, Guelph, ON, Canada N1G 2W1

e-mail: jsheeshk@uoguelph.ca

D. C. Cole

Department of Public Health Sciences, Faculty of Medicine,

University of Toronto, Toronto, ON, Canada

D. Kraft

Strategic Communications, Toronto, ON, Canada

A. Waugh

Upper Grand Family Health Team, Fergus, ON, Canada manage this risk. The paper concludes with a discussion of these benefits, risks, and risk management strategies as ways that Great Lakes fish consumers "construct" rather than "perceive" risk. We advocate for risk assessment and management protocols that involve those who will be affected the most, such as frequent consumers of Great Lakes fish, from the initial "risk characterization" stage through to any necessary risk communication.

Keywords Environmental exposure $\cdot$ Environmental justice $\cdot$ Ethnic groups · Fish consumption · Food contamination - Great Lakes fisheries - Ontario · Canada $\cdot$ Risk communication $\cdot$ Risk perception

\section{Introduction}

Over the last three decades, evidence that individuals who eat considerable amounts of Great Lakes fish have greater exposure to persistent toxic substances has continued to mount, resulting in concerns about adverse affects on human health (Johnson et al. 1999). Estimates of risks (e.g., Stern 1993) or risks and benefits (Ponce et al. 2000) from eating contaminants and nutrients in fish have been generated. Audience assessments for fish advisory information have been carried out (Burger and Waishwell 2001; Velicer and Knuth 1994) and presentation formats for fish advisory information tested (Connelly and Knuth 1998). Even so, incomplete adherence to risk reduction recommendations is common in the Great Lakes (Tilden et al. 1997).

Many studies of risk among fish consumers utilize the concept of "risk perception" and use psychometric approaches to measure this construct. Inherent are a set of distinctions: lay people perceive risk, scientists measure 
risk, and policy makers and agency personnel manage risk. These distinctions often carry pejorative overtones. Lay people's perceptions are interpreted as ill-informed and biased (Lupton 1999) and are explored only as a means to better overcome resistance to the judgments of scientists and advice of agency personnel (Hansen et al. 2003), for example, the study by Levine et al. (1999) on angler attitudes, beliefs and behaviors in relation to the Michigan Fish Consumption Advisory.

Yet some social scientists understand risk to be a social, political, cultural, and even a moral construct. In fact, two decades of social science writing on the subject of risk has championed social constructivist approaches over purely positivist understandings of risk as an objective or valuefree numerical expression of a probable negative outcome. Rather than seeing risk as something determined by scientists and managers on behalf of a lay public, social scientists view risk as defined, debated and managed by all involved - both experts and the public (Douglas 1992; Fox 1999; Inhorn 1995; Lupton 1993; Nelkin 1989; Short 1984). Anthropologists and sociologists have explored notions of risk associated with fish consumption in studies of so-called vulnerable populations, e.g., African-Americans (Beehler et al. 2001), the urban poor and people of color (Corburn 2002), and Aboriginal people (O'Neil et al. 1997). As part of a larger inter-disciplinary project on frequent (more than 26 meals/year) consumers of Great Lakes fish in Ontario Areas of Concern (Sheeshka and Cole $2000)^{1}$ we relied on both positivist and constructivist notions of health risks and benefits. The project was initially conceived as a survey of "at risk groups," targeting the locales with the most pollution and the people who ate the most fish (Murkin et al. 2003). However, candid, insightful and challenging conversations with fishers from many different backgrounds soon told us that issues of risk and benefit were complex, carefully considered, and contested. The question was no longer "Who is at risk?" but rather "Who defines risk?"; not only "Who follows fish consumption advice?" but also "How should consumption advice be developed and shared?"; not only "How do fishers perceive risk?" but "How do fishers and risk assessors alike balance risk and benefit?"

In this paper, we report findings from the qualitative component of the project, exploring issues of benefit, risk, understanding, and meaning from the perspective of the fishers themselves and in their own words. Unlike much of the writing on the risks and benefits of fish consumption-

\footnotetext{
${ }^{1}$ In 1985, the International Joint Commission's Great Lakes Water Quality Board identified 42 "Areas of Concern" around the Great Lakes. These locations, commonly referred to as "AOCs," were accorded this acronym based on the extensive point source pollution and destruction of fish and wildlife habitat occurring within their boundaries.
}

which has the narrow scope and urgent practicality of a health protection mandate-this paper takes a broader approach to the issues. By interpreting the words of frequent fish consumers in the context of contemporary social science thinking on risk, and taking our cue from risk research conducted in partnership with environmental justice activists (Corburn 2002), we advocate for wider recognition of the meaning and importance of eating Great Lakes fish to fishers and their families, and recommend greater involvement of affected communities in research and decision-making.

\section{Methods}

The principal method of collecting qualitative data for this project was through audio-recorded, semi-structured interviews generally lasting $45-75 \mathrm{~min}$ and conducted in each participant's home. The interviews covered 23 topics across five areas: benefits of fishing and eating fish, perceived risks of eating fish, personal protection, management of the fishery, and feelings and practices related to food in general. The interviews were supplemented by field notes kept by all research staff interacting with participants. Qualitative methods, by stimulating participants to tell their stories and share their understandings, enabled documentation of alternative perspectives (Eyles 1993), revealed the unexpected, and generated novel hypotheses (Thornton 1993). The data were in the form of words rather than numbers. Analysis and interpretation offered explanation and understanding rather than statements of fact, and the analytic emphasis was placed on variability within a small group rather than on the capacity to generalize results to a larger population. Finally, the advantage of qualitative methods for this study was the production of detail and depth rather than scope and breadth (Denzin and Lincoln 1994). Qualitative methods have been recommended for use especially in studies of food risk in general (Hansen et al. 2003; Knox 2000) and risk from fish consumption in particular (Beehler et al. 2001) because feelings and beliefs about food are greatly influenced by social, cultural and historical contexts.

\section{Participants}

Potential recruits came via three sources (Sheeshka and Cole 2000): (1) key informants, social and religious community organizations, newspapers, health fairs, and personal contacts in the Chinese and Vietnamese communities of Metro Toronto and Hamilton, which previous research had indicated might be frequent sport fish consumers (Cavan et al. 1994; Kraft 1995); (2) a parallel 
study which interviewed shoreline fishers at popular fishing spots in Metro Toronto, Hamilton Harbour, and along the Canadian sides of the Niagara, Detroit, and St. Clair Rivers (Fish and Wildlife Nutrition Project 2000); and (3) family members, friends or acquaintances of potential recruits.

Eighty-seven tape recorded interviews were conducted with 90 of the 91 study participants. One Vietnamese woman chose not to participate in the tape-recorded long interview. Forty-eight interviews were in English, 37 in Vietnamese, four in Cantonese and one in Mandarin. Participants in the study had eaten a minimum of 26 and an average of 108 Great Lakes fish meals over the 12 months prior to their interviews. Participants provided informed consent and were compensated for time spent on the study in keeping with approval granted by the McMaster University Faculty of Health Sciences Research Ethics Board.

We chose to present findings from our diverse sample of interviewees by separating them into two categories: "Asian-born" and "Euro-Canadian." These categories provide a relatively simple way of highlighting similarities and differences across and within participant groups according to cultural and geographic criteria. "Asian-born" refers to those participants who came to Canada from Viet Nam, China or the Philippines, either as immigrants or refugees. The Filipino participant was the sole Asian-born individual to have an interview conducted in English. "Euro-Canadian" participants were either born in Europe or were Canadians of European heritage. All 47 of the Euro-Canadian interviews were conducted in English by the dietitian. Two research assistants conducted interviews in Vietnamese and two conducted the interviews in Cantonese and Mandarin.

The demographic characteristics for all study participants (including one woman who did not complete a taperecorded long interview) are presented in Table 1. Overall, there were $44(48 \%)$ women and $47(52 \%)$ men in the study ranging in age from 17 to 64 years, yet disproportionately more women were in the Asian-born group and disproportionately more men were in the Euro-Canadian group. Unlike the male participants-all of whom were fishersjust over half (22/43) of the women we interviewed were actively involved in fishing. Household income was generally higher among Euro-Canadian participants, with fewer participants (26\%) earning less than $\$ 30,000$ compared to the Asian-born participants (75\%). Asian-born respondents were more likely to be keeping house (47\%) and less likely to report working (37\%) than Euro-Canadians. Fewer Euro-Canadian participants than Asian-born participants had completed only primary school ( $2 \%$ vs. $18 \%$ ), and more Euro-Canadian participants had some level of college or university education (38\% vs. $18 \%$ ).
Table 1 Demographic information by country of origin

\begin{tabular}{|c|c|c|c|}
\hline & $\begin{array}{l}\text { Asian- } \\
\text { born } \\
(n=44)\end{array}$ & $\begin{array}{l}\text { Euro- } \\
\text { Canadian } \\
(n=47)\end{array}$ & $\begin{array}{l}\text { All } \\
\text { participants } \\
(n=91)\end{array}$ \\
\hline Age (mean) & 37.6 & 36.3 & 37.1 \\
\hline Gender (\% male) & 34.1 & 68.1 & 51.6 \\
\hline \multicolumn{4}{|l|}{ Family income } \\
\hline$<\$ 30,000$ & $33(75)^{\mathrm{a}}$ & $12(26)$ & 45 (49) \\
\hline$\$ 30 \mathrm{~K}-\$ 59.9 \mathrm{~K}$ & $3(7)$ & $18(38)$ & $21(23)$ \\
\hline$\geq \$ 60 \mathrm{~K}$ & $2(5)$ & $7(15)$ & $9(10)$ \\
\hline Not given & $6(13)$ & $10(21)$ & $16(18)$ \\
\hline Mean & $\$ 21,000$ & $\$ 40,900$ & \\
\hline \multicolumn{4}{|l|}{ Main activity } \\
\hline$\%$ working & $37 \%$ & $60 \%$ & \\
\hline $\begin{array}{l}\% \text { keeping } \\
\text { house }\end{array}$ & $47 \%$ & $2 \%$ & \\
\hline \multicolumn{4}{|l|}{ Education } \\
\hline Primary & $8(18)$ & $1(2)$ & $9(10)$ \\
\hline $\begin{array}{l}\text { Some high } \\
\text { school }\end{array}$ & $12(27)$ & $14(30)$ & $26(29)$ \\
\hline $\begin{array}{r}\text { Completed } \\
\text { high school }\end{array}$ & $15(34)$ & $14(30)$ & $29(32)$ \\
\hline $\begin{array}{l}\text { Some College/ } \\
\text { University }\end{array}$ & $5(11)$ & $9(19)$ & $14(15)$ \\
\hline $\begin{array}{l}\text { Completed } \\
\text { College/ } \\
\text { University }\end{array}$ & $3(7)$ & $9(19)$ & $12(13)$ \\
\hline $\begin{array}{l}\text { Refused to } \\
\text { answer }\end{array}$ & $1(3)$ & & $1(1)$ \\
\hline $\begin{array}{l}\text { Mean \# years } \\
\text { of schooling }\end{array}$ & 10.6 & 12.7 & \\
\hline $\begin{array}{l}\text { Mean \# years } \\
\text { in Canada }\end{array}$ & 6.8 & 31.4 & \\
\hline
\end{tabular}

${ }^{a}$ Percentages are column percentages within each cell

\section{Interviews}

The dietitian and interpreters were given training in semistructured interview techniques, provided with a copy of a qualitative training manual designed for the project, and given both written and oral feedback on early interviews. Field trips were arranged to allow both the dietitian and interpreters the opportunity to learn the shoreline lingo-be it in Cantonese, Vietnamese or English. Learning the vocabulary of the participants was considered a priority, not only in terms of building rapport and credibility with fishers, but also as a way of gaining insight into what questions to ask, how to ask them, and when (Bernard 1994).

Interviewers were provided with a comprehensive interview guide as a pre- and post-interview reference that outlined general themes, topics to explore, sample questions and suggestions for follow-up to these questions. The interview itself had a conversational feel to encourage open 
and honest communication and to provide the flexibility to explore the interviewee's areas of interest or expertise. In interviews conducted in Vietnamese or Chinese, the interpreter, as a cultural insider, was encouraged to make a connection with the interviewee and approach the interview in an appropriate and empathetic manner. Such an approach can positively influence both the participant's experience of the research process and the quality of the data that is generated (Dyck 1993).

\section{Translation and transcription}

All five of the Chinese interviews and three of the Vietnamese interviews were translated by the individual who conducted the interview, while the remaining Vietnamese interviews were translated by a Vietnamese translator who was hired specifically for this task. All translators were instructed to initially transcribe the taped interview wordfor-word in the original language. The research team and translator together refined the interpretation of ideas, concepts, idioms, and culturally-specific references, and clarified any confusing or ambiguous aspects of the translation, through intensive back-and-forth discussions about each translation as it was completed. Verbatim transcriptions were made from the tapes of interviews conducted in English and were checked against the tape by a member of the research team. Translators and transcribers were requested to include background noises; side conversations; any hesitation, stuttering, repetition or incomplete thoughts; and to note any laughter or chuckles.

\section{Interpretation and coding}

Data collection for the project spanned three years. The story told by the participants through their interviews was built slowly and successively as each translation or transcription was received and read. Important thematic issues were discussed during team meetings. Once all the qualitative data were received, interviews were coded according to thematic categories relevant to the study objectives and those important to the interviewees themselves. Interviews with Asian-born and Euro-Canadian participants were coded separately, both because topics raised during the interviews were sometimes different and because much of the overall analysis in the project was organized according to country of origin.

Two master files were prepared, grouping excerpts of text from all interviews under each of the thematic categories. These files included any statements offered by interviewees that seemed to differ from the majority of the participants in order to accurately reflect the data set and recognize the variability in the sample. A guide to qualitative analysis was prepared for team members and a listing of codes used in the master files generated. Team members consulted and compared findings with other researchers and discussed important or confusing issues with our translators-particularly regarding the content of interviews with Vietnamese-speakers-to increase confidence in interpretation. Such checking can be seen as part of a wider strategy of triangulation employed in the qualitative component of this project. Triangulation can be loosely defined as "the use of multiple methods" in an attempt to "secure an in-depth understanding of the phenomenon in question" (Denzin and Lincoln 1994, p. 2). Specific approaches included in our strategy were "investigator triangulation," in which other team members listened to the English language tapes and coded a selection of transcripts; "data triangulation," in which data from a variety of sources were used (e.g., long interviews, field notes describing observations, fish consumption data as per Murkin et al. (2003); and "interdisciplinary triangulation," in which the perspectives of other disciplines were incorporated into analysis (Janesick 1994). Our findings on risk and benefit are presented here as narrative summaries, supplemented by a selection of direct quotations from interviews. The latter illustrate our argument and interpretations, evoke the feeling and meaning of the interviewee's words, and permit alternative interpretations.

\section{Findings}

Perceived benefits of eating Great Lakes fish

Superiority of freshly caught fish

The incomparably good taste of fish, especially when caught, prepared, and eaten almost instantly, was perhaps the most important benefit of eating fish from the Great Lakes. Freshly-caught fish was unanimously considered superior in quality to the pre-packaged fish available fresh or frozen at the market or grocery store. As one participant explained, "The quicker you get it from water to stomach, the better." But for many Euro-Canadian participants, an equally important advantage to eating your own catch was quality control. Other studies have shown that perceptions of high quality, positive food choices are linked to a participant's everyday life and experience and negative appraisals are associated with things outside the interviewee's experience (Hansen et al. 2003). Our interviewees spoke with suspicion about the way fish were "handled" on commercial vessels. One asserted, "You don't know what frigging salty sea dog has his dirty hands all over the fish or whatever." Interviewees expressed concern over the quality of store-bought fish, the care taken in cleaning and storing them, and the possibility of bacterial contamination. One stated: 
In the market I don't know how old it is, I don't know how fresh it is, I don't know where it was caught. They don't even know where it was caught. I don't know who handled it; I don't know how it's been cleaned. I'd rather catch it myself and so I know. From its swimming to being in my stomach, I know exactly what's happened to that fish.

\section{Sharing with extended family and friends}

Asian-born participants, more than Euro-Canadians, spoke of pooling fish caught and redistributing the catch of the lucky or skilful to family and friends who were less fortunate that day. But sharing fish happened off the shoreline, too. Many of the participants we interviewed-both Asianborn and Euro-Canadian-spoke of giving fish to others after bringing it home. Some lucky visitors-including the project's dietitian-were invited by participants to raid overly-full freezers. A few participants, when asked if recipients were happy or appreciative, modestly replied "I guess so" or "They seem to be." Most, however, conveyed the value of their fish gifts in less restrained terms. One woman, for example, enthused, "Everybody almost kiss my hand. They love it."

Fish could be shared cooked as well as raw, and a frequently discussed and much enjoyed way to share fish was as a meal eaten with friends and family. Sharing prepared fish could happen at home or on shore. Shoreline meals meant that fish could be eaten at its freshest; friendshipssome built and sustained only through shoreline contactcould be renewed and reinforced by eating together. One interviewee told us:

Back when the Jumbos [Jumbo Perch] were running a month and a half ago, me and a friend and his brother were fishing the Hydro every day and we were feeding just about everybody down at Hydro that come down. With fish crisps. We'd have one box of fish crisps would do 14 pounds of fish and we'd go through a box a day. We were going through a lot of Perch. Everybody really enjoyed it... people we didn't even know.

Participants often hosted dinners for friends, family and neighbors. Whether spontaneous or eagerly anticipated, low-key or elaborate, these events were opportunities to share the success of a good day or a good season, and offered a chance to share the fisher's enthusiasm for the sport. As one interviewee remarked, "If I catch a whole slew of fish in a day or something, I'll have a great, big cook-off ... You just have a good time, sit around and eat fish and," he laughed, "tell stories." Another interviewee said:
I can't throw fish back. I got a family here that are just fish fanatics. I got a lot of guys coming over like [friends' names] upstairs and their wives and friends of mine and all my family. When I have a fish fry I got to make sure I got enough fish to feed everybody. Nobody leaves hungry.

\section{Identity}

Catching and eating fish, according to our Asian-born participants, was also about "being Asian," and about maintaining cultural and culinary continuity in a new country. Fishing became a way to distinguish "self" from "other" and "Asian" from "Canadian." "You may notice that those who say 'don't eat' are, like, the Canadians or the Whites. Catch and release, we don't believe that, no," laughed one participant originally from the Philippines. "Western guys," a Vietnamese-speaking interview claimed, "go fishing for fun, they just fish for fun only. They don't take it." A third participant who did not often go fishing herself learned of the "Western" catch-and-release phenomenon from watching TV fishing shows. Unable to conceive of letting the fish go as part of the fun of fishing, she decided that TV fishers were "conducting experiments."

It is important to note that this typology of "ethnics" as "eaters" and "Canadians" as "releasers," although based in immigrant experience, does not appear be a true representation of all Canadians. In the most rural area from which we recruited participants to this project-communities along the St. Clair River-two-thirds of shoreline fishers surveyed in a partner project ate some or all of their catch from the river (Dawson and the Fish and Wildlife Nutrition Project 2000). This was also the survey area that had the lowest proportion of fishers born outside of Canada. Thus the eater-releaser typology discussed by immigrant participants may be as much a product of a difference in urban and rural Canadian attitudes and behaviour as it is a difference in the tastes and habits of newcomers and acculturated Canadians.

Interviewees born in Canada were less likely to describe their love of fishing and eating fish as being part of their cultural identity compared to Asian-Canadians. A number of interviewees did, however, assert that there was a link between eating their catch and role fulfilment within a nuclear or extended family. They took pride in the fact that their families were eating the products of time spent on the shoreline and clearly conveyed that eating fish caught yourself were signs of self-sufficiency, productivity, and skill. One interviewee explained, "You knew you caught it. You had the fun time with, you know, the fight, the battle. You're sitting there eating it. I guess it's a rush." Another noted, "No matter how broke we are, we can always go out 
and go fishing and eat it... Everybody has hard times but you always know when you're a sport fisherman, you can always go out and catch your own food." Another asserted:

I never buy it. Never. I always catch it. If I'm going to eat fish, I catch it. That's the fun about catching something you want to eat. Why go buy something that's already been caught? It spoils everything. 'Oh, look at that big sucker. Did you catch him?' Yeah, it gave me about a $10 \mathrm{~min}$ fight. From the freezer to my shopping cart. Big deal.

\section{Economic benefit}

It was the rare fisher who explicitly stated that fishing helped with the grocery bill. Once this subject was raised, most of the fishers we interviewed tabulated the cost of gas, lures, food, smokes, coffee, line and their initial investment in equipment, and almost unanimously considered buying fish to be cheaper. Both Asian-born and Euro-Canadian participants emphasized that they fished for fun, peace and relaxation, and a chance to be outdoors, not because they needed food. Some fishers, however, acknowledged that if they didn't eat their own catch they would likely not eat as much fish. Some were concerned about the cost of fish at stores and markets and preferred to buy other food. Others, while stating that they enjoyed eating the fish they caught themselves, were concerned that a purchased substitute would be poor, both in terms of quality of fish and quality of experience.

Interviewees sometimes put a dollar figure on their catch. As one said, "If I come home and I clean up my fish and I've got 5 pounds of fillets, I think well, there's \$50CA worth of fish. 2 Just for going out and having some fun." Others thought of the cost of inviting the neighborhood to a store-bought fish or meat dinner. "Two fish fries, maybe 60 people at both fish fries, $\$ 10$ a person, that would be 600 bucks, \$1,200 just for two fish fries." Another, who had recently cooked 80 perch for a party of eight, noted, "I know if I wanted to have six or eight people up and cook roast beef or something like that, my God, I'd spend like 20, 30, \$40 for a roast."

It is important to discuss these findings in the context of Joanna Burger's (Burger 2002) article on the reasons people fish. She suggests that because survey respondents fishing in Newark Bay reported that they fished to "be outdoors" and "commune with nature" rather than "for food," these fishers may be amenable to converting to catch and release as a means of guarding against contaminant intake. Our findings would suggest that although

\footnotetext{
${ }^{2}$ At the time of the study, this would be approximately $\$ 58.80$ US.
}

fishers do not immediately describe their activity as motivated by economic need, they appreciate the opportunity to regularly and widely share their catch with family and friends - a luxury that they could not afford if they had to purchase fish or meat - and that they associate catching and eating fish as part of their identity. To admit to fishing "for food" may imply short-sightedness, irresponsibility and poverty, but this does not mean that the end result of a good day's fishing - plentiful fresh fish eaten in the company of family and friends-does not have great value to fishers.

\section{Health benefits}

When asked about the health benefits of eating their catch, rarely was the reply extensive, enthusiastic or elaborate. Treatment of health benefits contrasted starkly with issues such as conservation, corporate polluters, the commercial fishery, catching "the big one," recipes, and hosting fish fries, all of which elicited detailed, lengthy, interesting, and at times emotionally-charged anecdotes and opinions. The core of many replies regarding health benefits was that, compared to "red meat," fish was a superior food. Participants described the two as dichotomies. For example, fish is good and meat is bad; fish has no fat and meat is fatty; fish is easy to digest and meat is difficult to digest. For Euro-Canadian women in particular, fish was considered a fat-free or low-fat alternative to meat, hence was a feelgood, guilt-free food. Fish was considered high protein, believed to contain good fats, appeared to provide important vitamins and minerals and, as some joked, fish was "brain food." Some Vietnamese interviewees recommended eating fish to prevent goiter. Yet, in several cases the closing comments on benefits focused on concerns about contaminants and the impact that chemicals had on these otherwise healthy attributes. "I think eating fish is good for you but with all the toxins I don't think it's $100 \%$," one participant concluded.

Perceived risks of eating Great Lakes fish

\section{Ignoring risk}

Many of the interviewees did not discuss fish consumption using terms such as risk or risky; instead these were terms introduced to discussions by interviewers through questions or clarifications. Rather than speak about "risk," most participants preferred to describe themselves as being-or, as was often the case, not being_- "worried," "concerned," "scared," "afraid," and "nervous" about eating fish.

The interview was not the first time participants were asked about their fish consumption. Several interviewees 
described defending their fishing and fish-eating practices to friends, relatives and curious strangers. Participants reported that reactions to their local fish consumption ranged from incredulous disbelief ("You eat the fish?") to disgusted judgments ("How could you eat it? It's all got chemicals in it") to strict admonishments ("Well, you shouldn't eat the fish out of the river."). Such comments were received by participants with a frequency which they experienced as disturbing. "I hear it all the time. I heard it even today," one interviewee noted. "I get that from the girls at work all the time," another interviewee admitted. "They're saying, 'Oh, you really eat the fish from out of the river? I wouldn't eat those fish, they're full of mercury'."

A common reaction by Euro-Canadian interviewees to comments and questions which would otherwise incite worry or concern was a shrug of the shoulders and an offhand remark like, "if they don't want to eat 'em, that leaves more for me." For some interviewees_-particularly those who had been eating fish "all my life" or "ever since I could remember" - fish consumption was a "kind of in the back of your mind concern." But the costs of succumbing to the worry or focusing on the concern were too high. One participant remarked, 'I just don't let it bother me. I'm not going to let that change my life." Another, when asked if he was concerned about health effects, admitted, "No. Because it'll scare me now and then I'll never eat fish anymore and I like eating fish. No, I don't worry."

Some of these interviewees compared fish consumption to other "unhealthy" pleasures like smoking, alcohol, or as one participant admitted, drinking 14 cups of strong black coffee a day. "I don't worry about the future when it comes to health because if I'm going to die, I'm going to die and if I'm going to live, I'm going to live," one participant explained. He added with a laugh, "I do smoke, I drink beer, I don't take vitamins, I don't follow a diet." Another noted,

I smoke a lot. I smoke a pack, a pack and a half a day. Sure there's chemicals in there. But hey, that's just the way I am. I don't worry about it. If you did, you wouldn't do anything. You'd sit in a chair. And you'd never move.

A number of participants who had recently arrived in Canada either as immigrants or refugees responded to interviewer inquiries about worry or concern with a similar laissez-faire attitude. Rather than choosing to ignore or repress cautions and concerns, however, they argued that life and death decisions were beyond their control. They suggested that the future was pre-ordained and that it was a typically Canadian or Western response to be "too much afraid" or "willing to live too much." As one Vietnamesespeaker acknowledged:
I'm different from the Westerners. The Western people, they value their lives. I don't treasure mine (chuckling). That's why I just eat it and whichever day I live, I'm happy for that day (laughing). The poor people do not treasure their lives as much as the rich people... I considered myself dead once I was on the refugee boat ... Then having got to here, why would we be afraid of dying from eating contaminated fish (laughing)?

\section{Lack of evidence for concern about health effects}

Participants often explained a lack of concern about the risk from fish consumption by stating, in a manner that ranged from matter-of-fact seriousness to black humor, that they or others they knew had not yet experienced effects that would cause them to be concerned. One participant remarked, "I haven't started glowing in the dark or anything." Another joked, "I'm eating every day or every other day and I'm still alive. Or maybe that's why my attitude is like this. Maybe it's the effect of the fish, I don't know (laughs)." For those participants who believed that eating contaminated fish would cause acute and short-term illness, lack of effects was concrete evidence that-to date, anyway-the fish had done no harm. Expectations of shortterm illness varied. Vietnamese-speakers, for example, often understood "poisonous" or "contaminated" fish to cause an allergic reaction that would take the form of an itchy, red "rash," "pox," or "skin outbreak." Other participants, both Vietnamese-speaking and Euro-Canadian, expected sickness from fish consumption to closely resemble food poisoning.

However, several other participants, both Euro-Canadian and Asian-born, understood that the effects of eating contaminated fish were more insidious, cumulative and "serious." As one interviewee acknowledged, "At low levels, they could cause some long term sickness and it is active in the body and we don't even know it." These participants mentioned cancer, change in cellular "organization," memory loss, and "effects on the brain." Did such realizations alter their attitude towards eating Great Lakes fish? Participant responses indicated that some would rather ignore the future given the uncertainty of negative health outcomes, the paucity of information available on potential effects, and the likelihood that these effects would be felt many years hence than fixate on what might never happen and ruin a perfectly good way to spend time. One participant acknowledged: "What's done is done, you can't change the past so you've got to just keep going on. It would take a long time for any repercussions of eating fish from the river to happen, so I don't even think 
I'll live very long to see those." Another interviewee, who seconds before had clearly articulated the steps he took to minimize his risk, closed with this comment: "I know I'm not going to live long enough to accumulate enough of this stuff to do me any harm and even if it does, I'm not going to worry about it."

While the health effects that might be experienced by the general population were often discussed with hesitation and sometimes discounted, those who were aware of the recommendations for women of reproductive age were less confused by, and were even critical of, such advice. The idea that unborn babies were vulnerable and that women should alter their behavior was not questioned by these participants. While very few offered insight into the possible effects on a fetus, a number-all of them EuroCanadian-commented that pregnant women should exercise caution when eating Great Lakes fish or abstain altogether. This information came from a variety of sources, such as television programs, magazines, physicians, and Ontario's fish consumption advisory.

\section{Risk in context}

Participants discussed, and often downplayed, their concerns about Great Lakes fish in the context of other, equally important or uncontrollable risks they took or were exposed to daily. Many participants had not been born in Canada but had immigrated to this country as adults. Because of this, they were able to compare the risks from Canadian fish consumption with their understanding of environmental conditions in their home countries. As one participant stated, "If you say the fish here is unsafe to eat, then the fish in Taiwan should be completely inedible." A participant originally from the Philippines claimed, "Your bad water here is still clean back home." A woman who had emigrated from Romania asserted, "I think they [Canadians] are too concerned about this pollution. It's not so bad. They should know what's over the borders and just compare it but they don't have any comparison. That's why they are so worried about it." A woman originally from Poland remarked, "I cannot say that it's not polluted in Canada, but we cannot compare this pollution with pollution in Poland. Or Russia, or Czech area or another country."

Pollution and poverty were intimately linked. A woman originally from Viet Nam spoke of pesticides killing fish. "The dead fish," she explained, "many families, they admitted if they could net those, they would take them and they would eat them. The fish resource in Viet Nam is very scarce... There are no resources, so whatever is dirty is also considered clean, it has to be used as well." Another Vietnamese-speaking woman noted:
In Viet Nam, we eat fish just for the sake of eating fish. For sure in the country, the war country, for sure everywhere is polluted (chuckling). But I had never been concerned. Why? Because no one had provided any kinds of information about the environment. So we didn't know. We weren't aware, so who cares. We just eat and we don't have enough food because we are a poor country, right? Whatever we can catch, we can have it because foods are the first priority in my country.

Most Canadian-born participants lacked direct experience of global pollution levels and world poverty. Even so, they too viewed their risk from Great Lakes fish consumption in a wider-if more local than global—context. Some offered a generic assessment of the risk to which they were exposed daily: mad cow disease, carbon monoxide poisoning, a lightning strike. One stated, "I'm more worried about getting in the car and driving to the store... People die every 17 seconds, or something like that, in Ontario, in a car crash. People don't die every $17 \mathrm{~s}$ from eating fish." Other participants focused their comments specifically on environmental health risks. A number were concerned about the quality of their drinking water, specifically mentioning chlorine, sulfur, lead and contamination from nearby oil wells, and wondered at the ability of water treatment plants to remove the very same chemical contaminants that were of concern in the fish.

Prime candidates for impromptu, intuitive comparative risk assessment were meat and produce available at the local grocery store. Participants mentioned injections of hormones and antibiotics into meat; chemical additives to animal feeds; and pesticides spread on crops, which were then consumed by cattle drinking and eating nearby, as adding to the contaminant burden and health risks from meat consumption. Fruits and vegetables that came from as near as the United States and as far as South America were regarded with suspicion as a result of the use of commercial pesticides, herbicides and fertilizers. One participant told us,

I have no concern [about eating Great Lakes fish] because I don't think there's anything you can eat nowadays that isn't contaminated of some sort. They just did an advertisement on the news yesterday that the ginseng that people are using for health conscious and that, they just found out in the States that they're treating it with pesticide that is banned and that so far, none of the ginseng should be used for human consumption. So, to me, I can't see where it makes that much of a difference.

Knuth et al. (2003) have recognized this desire for comparative risk information, especially for information that would compare risks from self-caught fish with risks 
from other food sources. The authors advocate for comparative information in future risk communication. Following is an excerpt from an interview with a young woman that is typical of many of the responses Canadianborn participants offered to questions about the risk from Great Lakes fish consumption. She told us:

Second hand smoke will kill you, first hand smoke will kill you, sun will kill you, cow's meat could kill you, cow's milk could kill you. Everything can kill you, so it's just basically a chance that I'm taking. There's a lot of factors of health risks, but there's health risks with everything. So, no, it's not changing my mind about eating [fish]... They show that smoke will kill you and people smoke around me all the time and I hate it. Stop. But, it's in the air. Pollution's in the air, we're breathing it in. So, I'd say I have thought about it, but then I've thought about everything else too, so, I'm not going to stop going for walks just because of the sun, you know?

\section{Belief in environmental improvement}

Many Euro-Canadian participants, particularly those who had grown up in southern Ontario and had fished local urban waterways for decades, expressed cautious optimism about the state of the Great Lakes. Such opinion was often offered when interviewees were asked if they felt worried or vulnerable because they ate Great Lakes fish. Interviewees cited various kinds of evidence that the lakes were improving: the return of wildlife and environmentallysensitive species such as Rainbow Trout, the improved health of birds, the clarity of the water and enhanced weed growth, the rarity of fish kills, a decrease in fish with "blisters" or "sores," and improvement in the smell of both the water and the fish.

On the St. Clair River, participants spoke about "bigger fines" and a "crackdown" on polluters, regular water monitoring, and well-publicized spill reporting, and the practice of cooling water before it was released back to the river. Those who fished Lake Ontario, the Niagara River and Hamilton Harbor also noted similar improvements. One Niagara River fisher stated:

We've come a long way since I was young... back in those days, the Niagara River was so full of junk that you could smell the chemicals from the top of the gorge. It was that strong. And now, I guess there's still stuff getting in there, that's leaching in from the dump sites that you read about. But, the water, at least it looks clean and it smells clean and it's a thousand percent better than it was. 'Cause you used to be able to see the oil, like the oil slicks. Just constant. And foam. And it was a smell... a sort of an acid, acrid smell... So, they've come a long way.

\section{A desire for more information on risk}

We have reported elsewhere (Dawson and Kraft 1998) that there is little consensus among policy makers, and scientists and environmental activists at local, national and international levels, regarding the risks of fish consumption. Such a situation is ripe for contradiction and confusion - on the part of both the experts and those who are personally affected by such information. News headlines from early January 2004, for example, warned against eating store-bought farmed salmon and newspaper articles became a confusing battleground between research findings of an "unacceptable cancer risk" and the US Food and Drug Administration's claims that benefits from fish consumption outweighed the risks. Our participants had received similar mixed messages:

You read one article or you'd hear one thing telling you how bad it was, that they were finding certain chemicals in fish and that oh, you shouldn't touch these fish at all and then a while later you'd hear exactly the opposite. Somebody else would say oh no, they got it all wrong, they're okay. And so after a while of this kind of stuff, you start thinking about it and think, Well, do they really know? Then you start relying on your own judgment. Thinking, Well, okay, maybe they're right. But, then maybe they're not. So, take a risk.

Given these at-times inconsistent messages and the uncertainty felt by participants, it should not be surprising that a number of participants lacked confidence in their risk assessment and called for additional information to assist them in understanding the issues and making decisions.

Vietnamese-speaking participants, in particular, were often uncertain about the source of chemical contaminants in fish and the effect eating such fish could have on people. They frequently characterized themselves as lacking the expertise necessary to make judgments and decisions, both because they were not scientists and because they were from Viet Nam. "I don't know anything much about the science," one Vietnamese-speaker admitted. He continued,

In Viet Nam, we don't have the equipment and time to conduct such experiments. Well, if we know the causes - the causes, that'll be good. Because we don't have the fish detector machine to see whether it's poisoned or not, that's why nobody knows. We humans, when we catch it, we just eat it. We don't know. It would be good if after coming home from 
the fishing place, we had a test machine at home to examine whichever fish had been poisoned. Since we have no idea about science, how could we know about that? (laughing) Right? When we catch a fish and we notice that it's good, fine, fleshy, and sweet, then we'll just eat it (laughing).

A number of Vietnamese-speakers understood that their participation in our research study was intended to fill such gaps in knowledge and to enable informed decision making. "That's why I phoned ["phoned" said in English] you to ask about this fish research and what it is, you understand?" one woman explained, adding, "Let's see how this project you're researching will come out to. Then later if they post it in books or on TV, newspapers, then we won't need to worry anymore."

\section{Managing risk}

\section{Choosing a location to fish}

Most Vietnamese-speakers, when asked what could be done to eliminate "toxins" or "contaminants" from fish, were reluctant to offer suggestions. The clear message from these interviewees was that, in the absence of definitive and credible precautionary measures, the best strategy was to avoid locations that might be polluted. Newcomers to Canada often first learned of potential problems at particular locations from friends, strangers on the shoreline-who were often termed "Canadians" - and rumor. Asian-born participants were not necessarily confident in hearsay and unsubstantiated comments, but without evidence to the contrary, these participants acted on information they willingly admitted might be questionable. One Chinese-speaker mentioned, "If someone tells you something, it doesn't hurt to believe their word." Asian-born interviewees, for example, avoided industrial areas and those with a nearby hydroelectric or nuclear power plant; locations with murky, cloudy or stagnant water; places where others wouldn't eat the fish; and places that others recommended avoiding.

Many Euro-Canadian participants looked for signs in the built and natural environment that were similar to those identified by Asian-born participants. Larger bodies of water-lakes like Lake St. Clair, Lake Huron and Lake Erie-were desirable. Participants spoke of keeping fish from "the middle" of these water bodies where deep water and distance from industry was presumed to keep contamination to a minimum. Some Euro-Canadians preferred to eat fish from moving water and rivers as opposed to "stagnant pools" or lakes. The presence of fast water currents gave confidence that everyday discharge and spills would be dispersed and diluted efficiently. A uniquely Euro-Canadian criterion for determining safe locations for keeping fish was the presence of certain indicator species such as crayfish or Rainbow Trout, which were known or reputed to be particularly sensitive or vulnerable to contaminants.

Participants eating fish from the St. Clair River showed an impressive knowledge of warm water outflows and discharge points. Many were suspicious of Talford Creek-widely recognized as an outflow for an oil refinery. Certain signs were interpreted as concrete evidence of dumping or discharge: unnaturally warm water; chemical smells emanating from water or fish; oil slicks, gasoline or a "rainbow color" on the water; fish with "cancers," "deformities" or which looked like "the Simpson's threeeyed fish"; and discarded household or industrial "junk." These were indicators that few ignored when speaking specifically about choosing locations based on the safety of the fish there. While some participants avoided fishing these spots or practiced catch-and-release only, others used discretion, keeping fish only at particular times of the year or only species that they were confident migrated through a contaminated area rather than residing in contaminated places year-round.

\section{Species eaten}

Interviewees chose to eat particular species of Great Lakes fish based on taste, availability and, occasionally, based on concerns about contamination. Walleye and Yellow Perch were the most popular species to eat among Euro-Canadians, while Rock Bass was the preferred species by Asianborn interviewees (see also Murkin et al. 2003).

Asian-born participants described an evolution or refinement in their taste for Great Lakes fish. As they became familiar with freshwater fish species available in particular locations they became "pickier" about what they would take home. It was through this trial-and-error taste testing that many of our participants who were newcomers to Canada realized that tough-fleshed Sheephead; "bony," "soft" Carp; and "smelly" Catfish were not the only fish in the lake. Euro-Canadian participants also considered these same species of fish to be undesirable. But while AsianCanadian interviewees politely critiqued the species' culinary characteristics_-perhaps after several failed attempts with different recipes-Euro-Canadians usually condemned these species for use in the human diet, often never having eaten a Sheephead, Sucker, Shad, Carp or Catfish. Most Euro-Canadian interviewees renounced these species for being "bottom feeders." One interviewee said with an audible shiver, "I've never tried it, people say it's good, but I still won't because they look like a dirty fish. They're sucking on the bottom and stuff like that. Yuck. It's really 
gross." In the hierarchy of the fish world, these species were at the bottom both literally and figuratively. The symbolism is powerful, especially in times of environmental contamination when fishers are concerned about chemicals in sediment.

\section{Identifying contaminated fish}

Practically everyone we spoke with had an opinion to offer about what characteristics distinguished a "healthy" fish from an "unhealthy" fish. Because many could only hypothesize on the cause of an abnormality and most admitted ignorance of the effect of a defect on a consumer, the tendency was to "throw back" anything that looked suspicious. In the absence of conclusive evidence that growths, parasites, fungus, worms, Lamprey eel attack marks, slashes from a boat propeller, and nibbles taken by other fish were benign and had no effect - either on fish or humans-participants chose to err on the conservative side and release these fish.

While "unhealthy" was certainly not synonymous with "contaminated," an understanding of indicators participants used to distinguish healthy and unhealthy fish gives insight into the keep-or-release decision-making process. It also clearly shows that participants did not consider themselves at risk from contaminants alone. Biological or bacterial contamination was also a concern when fish displayed open sores, "lesions," "cankers" or appeared otherwise "infected."

A number of our participants were confident about their ability to distinguish healthy from unhealthy fish. These interviewees claimed that their experience with a particular species, location, or with fishing in general gave them an intuitive ability to distinguish what was normal from what was deviant. But many of the assessments about unhealthy fish were acknowledged-by the participants themselvesto be little more than educated guesses, shoreline lore, resulting in a conservative risk management strategy.

When participants were specifically asked about chemical contamination and their ability to discern a contaminated fish from an uncontaminated one, many declined to offer definitive answers or to even hazard a guess. One participant acknowledged, "You can look for all the little things you've seen or learned over the years, but you'll never be able to tell specifically. It could look like the cleanest fish and there could actually be something wrong with it. You just don't even know."

\section{Keeping the small ones}

Participants who chose to eat smaller fish, almost all individuals who were Euro-Canadian, offered three reasons for this preference: (a) concern over contaminants, (b) improved taste and texture, and (c) a desire to protect breeding stock by releasing larger fish. For these participants, big fish offered fabulous "photo ops" and were perfect trophy specimens for hanging on the wall. But these fish were not prime pickings for the plate. These were certainly not mutually exclusive categories, and it was common for Euro-Canadian participants to combine various elements of the taste-contaminant-conservation triad in their decision regarding the size of fish they kept. Those participants who preferred to keep smaller fish employed personal guidelines, "cut-offs" with regard to smaller size, and rules of thumb to determine the ideal size of fish for eating. Some participants offered only a generic rule with no specific content. As one participant declared, "I eat everything 3 pound, 4 pound fish. I'm particular what I eat because I know what's going on." It was common for participants to have upper-limit size restrictions for larger fish like Pickerel, Pike, Salmon, and Trout but to have an anything goes or 'bigger is better' approach to keeping pan fish. It was felt that these fish, being inherently small, were safe to eat at any size. In fact, rather than offer a maximum size limit for Yellow Perch, participants often stated their keep-or-release rules in terms of minimum sizes.

While Euro-Canadian interviewees often spoke of the size-contaminant connection as if it were unquestioned and regularly acted upon, Vietnamese-speaking participants often intimated that such information had been recently learned and was privileged knowledge from outside sources like "Canadians," "books," or acculturated relatives. Participants described this recently-acquired knowledge as if it were a set of rules for safe fish consumption. But it was sometimes unclear from their comments whether these rules were actually followed.

\section{Cleaning fish}

For Asian-born participants, fish cleaning procedures were primarily about aesthetics and sometimes about minimizing risk from bacterial contamination. Interviewees shared techniques for removing slime, de-scaling, and for getting rid of unwanted fishy smells. Fish were disinfected by rinsing with vinegar, Chinese tea, or lemon juice and by rubbing with salt. Recipes prepared by Asian-born participants rarely required fish to be cut into fillets. In contrast, most fish species were filleted by Euro-Canadians, many of whom were careful to remove fat, belly meat and the "lateral line" or "mud line" because they were concerned about both taste and contaminants. Filleting was, however, considered inappropriate for species like sturgeon, catfish and bullhead and was eschewed by participants who did not like to "waste" any of the parts of these fish. Few 
participants scaled their fish since scaling was time consuming, messy and the skin was not appetizing on most species other than Yellow Perch.

\section{Limiting consumption}

Some project participants managed the risk from fish consumption by limiting the amount eaten or even ceasing to fish when they had concerns about the health of fish they were catching. This was especially true of long-time residents who had direct experience with the "mercury scare" of the 1970s and the degradation and recovery of the Great Lakes; these interviewees had eaten less fish in the past but were currently less concerned. Newcomers to Canada lacked this historical context and received information about fish contamination from news, rumor, and from the advertisement run in local newspapers to recruit participants to this project. While some Asian-born participants told us that they'd wait for concrete evidence that eating the fish would do harm before they'd adjust their eating habits, other participants had already restricted their consumption of fish in response to fears about contamination. Several claimed that they would eat more fish if those they caught "weren't contaminated" and one said that she ate fewer fish in Canada than in Viet Nam because of a concern over contaminants.

Both the quantitative and qualitative information collected for this project indicated that Euro-Canadians appeared to eat more fish in a meal than those originally from Asia (see also Murkin et al. 2003). Some Asian-born participants pointed to this fact as a reason for a lack of concern about contaminant intake. Euro-Canadian participants, while seemingly unwilling to relinquish the pleasures of feasting on platefuls of Perch, devouring pounds of Walleye, or snacking on smelt like "it's candy," often stated that there was no need to worry about contaminants because their overall consumption was not great enough to be a concern. The old adage "all things in moderation" seemed to be the underlying message from these participants. "I don't overdo it," one participant explained." I go in spurts. But, I would say once a week, tops." Another explained that he did not pay attention to Ontario's fish advisory because he didn't "eat a lot" of fish. "I don't worry about it," he told us. "If I was eating great numbers of fish then I would probably read the book, because I'm eating so much and it preoccupies a lot of my time. But since I don't eat a lot, I think I'm pretty safe."

It was not surprising to learn through the study that many participants did not consider Great Lakes fish, eaten in moderation, to be a concern. But what, exactly, was the accepted definition of "moderation"? Based on the results of previous studies, we set the cut-off for ingestion for recruitment to this study at 26 Great Lakes fish meals per year. The participants quoted above reported an annual consumption of more than 70 meals of Great Lakes fish. For many of the participants in this project, eating Great Lakes fish at least once if not close to twice a week was considered to be moderate, and even restrained, consumption. It seems, then, that the definition of moderation depends upon your perspective.

\section{Discussion}

A value-based construction of risk

Participants in this research project had consumed an average of 108 meals of Great Lakes fish in the year prior to being interviewed. These were individuals whose cultural identity, sense of self-worth, and place in family and community were defined to some extent by fishing, eating, and sharing what was caught. Purchased fish not only failed to meet these important social criteria, but failed to meet high standards of freshness and quality held by our interviewees.

References to the benefits of sport fish consumption often focus solely on nutritional benefits (e.g., Knuth et al. 2003) or imply that economically disadvantaged fishers were forced to rely on their catch for food (Burger et al. 2001; Corburn 2002). Our interviewees, however, did not place physiological health or economics high on their list of benefits. In fact, the manner in which both of these benefits were discussed by interviewees could be linked to the wider benefits of improved self worth (i.e., feeling good about what you ate) and social role (i.e., being a provider for family and friends). It is clear that eating sport-caught fish was intimately tied to our interviewees' sense of self and was, we would argue, a key value upon which their decisions were based.

The value of eating sport-caught fish-particularly from areas deemed "contaminant hotspots" - did not appear to be widely recognized outside of the community of fishers we interviewed. Cautious and negative attitudes towards Great Lakes fish consumption may also be found among scientists and policy makers. Dawson and Kraft (1998) interviewed a number of Great Lakes researchers and government employees and were repeatedly told that they wouldn't eat fish from Lake Erie, Lake Ontario or their connecting waterways. These scientists and health professionals, who "go fishing at the A\&P [a Canadian chain of grocery stores]," are in a position to influence public opinion about the state of local water bodies and may have input into local, national and international initiatives regarding the consumption of contaminated fish, yet they often do not share the values and understandings of fishing and eating fish held by our interviewees. 
Anthropologist Mary Douglas (1992) writes that risk and the designation of certain groups as "at risk" is a means of singling out groups whose attitudes or activities are deemed aberrant or dangerous. Fox (1999) describes society's attitudes towards risk as dependent on the moral or social value ascribed to the individual or activity; if the activity is seen to have redeeming social value, then the risk associated with it is downplayed. Leiss and Chociolko (1994) offer driving as an example of this; as a society we downplay the risks associated with this mode of transportation and minimize the impact automobiles have on the environment because of the significant benefit the majority of people realize from driving. If we were not becoming a more urban (or suburban) society; if we were not alienated from urban wild spaces, writing them off as dead and polluted; if we were not so distanced from our food sources and in particular, the means by which meat and fish get to the local store, would there be a greater societal recognition of the benefits of eating Great Lakes fish and a widespread downplaying of risk? In other words, if the majority of people valued the experience of fishing and the benefits of eating one's own catch, in the way most of the rest of us value automobiles and the freedom they provide, would we be less likely to see these activities as aberrant, putting certain groups "at risk"? Would we be more likely to pressure industries and government to take action to remediate contaminated areas?

Eating Great Lakes fish, however, is not a mainstream societal behavioral norm. Participants had been confronted by friends, family members, and strangers whose comments about degraded ecosystems and poisoned fish could easily make a frequent consumer of Great Lakes species feel abnormal. Attitudes toward risk may be adopted, not solely in relation to qualities inherent in a particular threat, but as a way of defending or reinforcing a particular social stance or valued activity, especially if aspects of this way of life was under attack (Douglas 1992; Joffe 2003). Comments like "I don't care," "things aren't that bad in Canada," or "I'm not dead yet" comprised the defensive armor of those who would otherwise be vulnerable to the value judgments of others.

But these reactions also belie the complexity of risk construction. Participants routinely outlined strategies employed by them to minimize and manage the risks of Great Lakes fish consumption. Their assessment of risk was influenced by their wealth of experience fishing in a particular location, sensory cues related the degree of health of fish, and especially by messages gained by speaking with fellow fishers on-and-off the shoreline. Many took special care to remove belly fat, the "mudline," and the skin when cleaning their fish. Others were careful to eliminate the risk of bacterial contamination through use of special cleaning and storage protocols. Some merely advised eating in moderation. Thus what might initially seem like an ostrich approach to risk-hiding from or ignoring risk-was actually little more than the immediate defense of value-oriented choices.

\section{Risk in context}

Many of the fishers we spoke with saw life as full of risks and food as fraught with danger generally. As Beck (1992) posits, concern over persistent toxic substances is merely one element of the "risk society" we live in, where individuals are continuously bombarded with the health impacts associated with every aspect of their physical environment and daily activity. Participants spoke of the risks incurred from pesticides, herbicides, hormones, smoking, driving a car, and drinking water, and saw fish consumption as only one risk among many that they took or were exposed to daily. Burger et al. (1998, p. 33) have labeled this "a form of habituation," where the perception of risk from fish consumption is reduced by a "bombardment" of risk messages on other issues. We, however, would view this same phenomenon as a form of comparative risk assessment, "risk-risk comparisons" which Knuth and her colleagues (2003) advocate being included in communication to fishers. Our participants did not make risk assessments in a vacuum or in isolation. We maintain that they had little trouble seeing issues in a wider context. Life experiences and the media enabled individual participants to make judgments about eating fish that took into consideration the risks inherent in alternatives.

Participants also recognized that there were no definitive answers to questions of risk, and often questioned their own risk reduction strategies. Could they really tell what was on the inside of a fish from its appearance? Could they really trust the advice of a stranger on the shoreline? They could take precautions to prevent bacterial contamination, but could they eliminate chemical contaminants? In the absence of definitive science, credible sources of information, or proof of concrete effect on their health, interviewees chose to employ risk reduction strategies at their disposal that enabled them to continue with a way of life they valued highly. Because of the anticipated loss of a highly-valued food source and damage to a strong sense of self worth and social/ cultural role fulfillment, the risk of not eating the fish caught from local Great Lakes waterways was considered greater than the risk of eating this fish.

Lessons for risk communication: engaging the audience

This project used a methodological tradition that not only provided unanticipated and nuanced answers to research 
questions but offers insight into what questions should be asked in the first place Richly-detailed data and contextconscious interpretation provided a deep understanding of the opinions, perceptions, and behavior of the fishers we interviewed. As a result, findings from the qualitative component of the project prompted the team to reconsider questions commonly asked by policy makers and by other researchers: "Why don't fishers follow fish advisories?", for example, evolved into an exploration of "How can fish advisories better respond to the needs of fishers?"

In the decades since the basic template of fish advisory programs was developed, changes in the communications environment have been dramatic. From private sector advertising to health promotion, messaging is more tailored to specific target audiences, and is calculated to engage individuals rather than to simply convey information. The "user" of information or "consumer" of a product is put at the center of any campaign, often assisting in the development and delivery of the message. The focus is shifted from expedient one-way transmission of information from expert to layperson-with the former assumed to have superior knowledge and the latter assumed to have attitudes and behaviors that need changing - to a long-term process of relationship-building that requires developing mutual respect of the different contributions various parties bring to the process (Bradbury et al. 1999).

Participants in this study, both Asian-born and EuroCanadian, were passionate about fishing and had already engaged in the issues to some extent. Some were clearly hungry for more information on fish safety and desired clear answers to questions about risk. All had adopted some means to reduce their risk, whether or not these were approaches recommended in government publications. And all participants recognized significant benefits to eating their catch. Results of this research argue for the possibility and appropriateness of designing a risk communication program from the perspective of the fisher: a program that informs the ongoing risk dialogue but does not pre-empt it, one that fosters multi-directional communication about such contentious and value-laden issues as consumption of contaminated fish, and also reinforces the significant social and cultural benefit that is associated with eating a Great Lakes catch.

There are examples of programs that have successfully integrated the values of both the scientist/policy maker and the affected community. Environmental justice activists have, in some instances, embraced community-based participatory research as a means of ensuring that the voice of disadvantaged communities is heard in research and decision making regarding environmental risks, including risk from fish consumption (Corburn 2002). Beehler et al (2001) suggest communicating risk about fish consumption to African-American anglers through respected community leaders who are also avid fishers and can act as "culturebrokers" between the scientific and fishing communities. While Beehler et al. would see these anglers as moderators of on-land fisher discussion groups, we would suggest that such an educational intervention, as it were, would best take place on the shoreline given the informal give-andtake relationships and sharing of expertise that already occur in the Great Lakes setting. Co-management programs have been developed in some subarctic and arctic Aboriginal communities where the traditional environmental knowledge of hunters, once discounted for being intuitive, subjective and based on a foreign and little respected cultural tradition, is being integrated with nonNative resource management (Johnson 1992). Finally, the Ontario Ministry of Natural Resources' Angler Diary Program, which enlists fishers to record their fishing days, hours, catches, and other details (such as bait and fish length) is an outreach strategy that builds relationships between a government agency and the public it is meant to serve. Diaries are ideally returned to their owner and presentations given on previous years' results, allowing government employees to stay in touch with the fishing public and fishers, so that there is ongoing input into management of the resource.

\section{Conclusion}

For both expert and lay publics, assessment of risk can be seen as built or constructed from knowledge, judgment, assumptions, experience, weighing of evidence, and values and dialogue. The term "construction" conveys an active process aspect of assessing risk and implies that risk is built in a social context, with different parties playing different roles and mutually influencing the outcome. While fish consumers acknowledge risks and work to manage them, they recognize significant benefits from eating their catch, which includes fishing behaviors that would be threatened by a preoccupation with risk and might be lost absolutely by converting exclusively to catch-and-release practices. Risk assessors and managers may not share the same values and social/cultural understanding of fishing and eating fish. However, the definition and management of risk must not promote one worldview at the expense of the other, but rather be a negotiated, democratic, collaborative process that begins and ends with those who have the greatest stake in the activity and the most to lose: the fish consumers themselves.

Acknowledgements Funded by the Great Lakes Health Effects Program, Bioregional Health Effects Division, Health Canada, Contract No. H4078-5-c388/001/SS. Tri-council Eco-Research Chair in Environmental Health at McMaster University. We are grateful for the contributions of the following research assistants: Hak Cheung 
and Charles Fok, Chinese community outreach coordinators, interpreters, translators; Cathy Dang and Mai Pham, Vietnamese community outreach coordinators, interpreters, translators; Mai Nguyen and Kim Nguyen, Vietnamese translators; Tracy Torchetti, anthropology graduate student; and Rachel Miles Derry, English language transcriber.

\section{References}

Beck, U. 1992. Risk society: Towards a new modernity. London: Sage.

Beehler, G.P., B. M. McGuinness, and J.E. Vena. 2001. Polluted fish, sources of knowledge, and the perception of risk: Contextualizing African American anglers' sport fishing practices. Human Organization 60 (3): 288-297.

Bernard, H.R. 1994. Research methods in anthropology: Qualitative and quantitative approaches. Thousand Oaks, CA: Sage Publications.

Bradbury, J.A., K.M. Branch, and W. Focht. 1999. Trust and public participation in risk policy issues. In Social trust and the management of risk, ed. G. Cvetkovich and R.E. Löfstedt, 117127. London, UK: Earthscan Publications.

Burger, J., J. Sanchez, and M. Gochfeld. 1998. Fishing, consumption and risk perception in fisherfolk along an East Coast estuary. Environmental Research 77: 25-35.

Burger, J., and L. Waishwell. 2001. Are we reaching the target audience? Evaluation of a fish fact sheet. The Science of the Total Environment 277: 77-86.

Burger, J. 2002. Consumption patterns and why people fish. Environmental Research Section A 90:125-135.

Cavan, K. R., B.L. Gibson, and M. Bui. 1994. Report for the Hamilton-Wentworth Department of Public Health Services on the Pilot Study of Dietary Habits of Immigrants of Vietnamese Origin. Parts I and II. Hamilton, Ontario, Canada: Health Canada.

Connelly, N.A., and B.A. Knuth. 1998. Evaluating risk communication: Examining target audience perceptions about four presentation formats for fish consumption advisory information. Risk Analysis 18 (3): 649-659.

Corburn, J. 2002. Combining community-based research and local knowledge to confront asthma and subsistence-fishing hazards in Greenpoint/Williamsburg, Brooklyn, New York. Environmental Health Perspectives 110(suppl. 2): 241-248.

Dawson, J., and D. Kraft. 1998. Communicating information about Great Lakes fish consumption: defining the problems and identifying the players. Community Animation Program, Health Canada Contract No. DB980318161459. Ottawa, Ontario: Health Canada.

Dawson, J., and the Fish, Wildlife Nutrition Project. 2000. Fish stories: A profile of fishing and fish consumption in the St. Clair River area. Great Lakes Health Effects Program Project Number K341813. Ottawa: Health Canada.

Denzin, N.K., and Y.S. Lincoln. 1994. Introduction: Entering the field of qualitative research. In Handbook of Qualitative Research, ed. N.K. Denzin and Y.S. Lincoln, 1-17. Thousand Oaks, CA: Sage Publications.

Douglas, M. 1992. Risk and blame: Essays in cultural theory. New York: Routledge.

Dyck, I. 1993. Ethnography: A feminist method? Canadian Geographer 37 (1): 52-57.

Eyles, J. 1993. Feminism and interpretive method: How different? Canadian Geographer 37: 50-52.

Fish and Wildlife Nutrition Project. 2000. Communicating fish advisory information: a monograph. Report to Health Canada
Great Lakes 2000 Program. Contract \# H4078-5-C385/001/SS. March.

Fox, N.J. 1999. Postmodern reflections on 'risk', 'hazards' and life choices. In Risk and sociocultural theory: New directions and perspectives, ed. D. Lupton, 12-33. Cambridge, UK: Cambridge University Press.

Hansen, J., L. Holm, L. Frewer, P. Robinson, and P. Sandøe. 2003. Beyond the knowledge deficit: Recent research into lay and expert attitudes to food risks. Appetite 41: 111-121.

Inhorn, M. 1995. Medical anthropology and epidemiology: Divergences or convergences? Social Science and Medicine 40 (3): 285-290.

Janesick, V.J. 1994. The dance of qualitative research design: Metaphor, methodology and meaning. In Handbook of qualitative research, ed. N.K. Denzin and Y.S. Lincoln, 209-219. Thousand Oaks, CA: Sage Publications.

Joffe, H. 2003. Risk: From perception to social representation. British Journal of Social Psychology 42, 55-73.

Johnson, B.L., H.E. Hicks, and C.T. De Rosa. 1999. Key environmental human health issues in the Great Lakes and St. Lawrence River Basins. Environmental Research 80: S2-S12.

Johnson, M. 1992. Research on traditional environmental knowledge: its development and its role. In Lore: Capturing traditional environmental knowledge, ed. M.J. Johnson, 3-22. Hay River, North West Territories, Canada: Dene Cultural Institute.

Knox, B. 2000. Consumer perception and understanding of risk from food. British Medical Bulletin 56 (1): 97-109.

Knuth, B.A., N.A. Connelly, J. Sheeshka, and J. Patterson. 2003. Weighing health benefit and health risk information when consuming sport-caught fish. Risk Analysis 23 (6): 1185-1197.

Kraft, D. 1995. Report on scoping to health Canada. Great Lakes Health Effects Program. Ottawa: Health Canada.

Leiss, W., and C. Chociolko. 1994. Risk and responsibility. Montreal, Canada: McGill-Queen's University Press.

Levine, K.J., V.D. Miller, M.A. Kamrin, and J.W. Dearing. 1999. Anglers' attitudes, beliefs and behaviors as impacted by the Michigan Fish Consumption Advisory. Journal of Public Health Management Practice 5 (6): 18-28.

Lupton, D. 1993. Risk as moral danger: The social and political functions of risk discourse in public health. International Journal of Health Services 23: 425-435.

Lupton, D. 1999. Introduction: Risk and sociocultural theory. In Risk and sociocultural theory: New directions and perspectives, ed. D. Lupton, 1-11. Cambridge, UK: Cambridge University Press.

Murkin, E., D.C. Cole, J.P. Kearney, J. Sheeshka, J. Dawson, and the Fish and Wildlife Nutrition Project. 2003. Fish consumption among fishers in five Ontario AOCs. Journal of Great Lakes Research 29 (3): 436-447.

Nelkin, D. 1989. Communicating technological risk: The social construction of risk perception. Annual Reviews in Public Health 10: $95-113$.

O’Neil, J.D., B. Elias, and A. Yassi. 1997. Poisoned food: Cultural resistance to the contaminants discourse in Nunavik. Arctic Anthropology 34 (1): 29-40.

Ponce, R.A., S.M. Bartell, E.Y. Wong, D. LaFlamme, C. Carrington, R.C. Lee, D.L. Patrick, E.M. Faustman, and M. Bolger. 2000. Use of quality-adjusted life year weights with doseresponse models for public health decisions: A case study of the risks and benefits of fish consumption. Risk Analysis 20 (4): 529-542.

Sheeshka, J., and D. Cole, eds. 2000. Great Lakes fish eaters project: Dietary survey and assessment of potential risks and benefits. Final report. Ottawa: Health Canada.

Short, J.F. 1984. The social fabric of risk. American Sociological Review 49: 711-725. 
Stern, A.H. 1993. Re-evaluation of the reference dose for methylmercury and assessment of current exposure levels. Risk Analysis 13 (3): 355-364.

Thornton, S.J. 1993. The quest for emergent meaning: A personal account. In Theory and concepts in qualitative research: Perspectives from the field, ed. D.J. Flinders and G.E. Mills, 68-82. New York, NY: Teacher's College Press.

Tilden, J., L.P. Hanrahan, H. Anderson, C. Palit, J. Olson, W. MacKenzie, and the Great Lakes Sport Fish Consortium. 1997. Health advisories for consumers of Great Lakes sport fish: Is the message being received? Environmental Health Perspectives 105: 1360-1365.

Velicer, C.M., and B.A. Knuth. 1994. Communicating contaminant risks from sport-caught fish: The importance of target audience assessment. Risk Analysis 14 (5): 833-841.

\section{Author Biographies}

Jennifer Dawson has a MA in Anthropology. In addition to her five years as Qualitative Research Director for the Fish and Wildlife Project, she has conducted research for the Law Society of Upper Canada, the Ontario College of Nurses, McMaster University, the Canadian Breast Cancer Foundation (Ontario Division), and Hamilton-based NGOs.
Judy Sheeshka is a Registered Dietitian and an Associate Professor at the University of Guelph. Her research focuses on food and nutrition policy, food security, risk communication, and the social and environmental determinants of eating behaviors.

Donald C. Cole is a physician-epidemiologist with over two decades of experience in applied environmental health. He currently teaches, mentors, does research, and contributes research evidence to public health practice both in Canada and internationally.

David Kraft is a Senior Consulting Associate with Strategic Communications Inc. In this capacity he designs advocacy campaigns, communication strategy and opinion research for many of Canada's most important not-for-profit organizations. Recent clients have included Greenpeace, the Canadian Breast Cancer Foundation (Ontario Division) and UNICEF Canada. David has an MA in Sociology.

Amy Waugh is a Registered Dietitian and works for a Family Health Team, an Ontario provincial approach to primary health care that brings together different allied health care providers to work with family physicians to coordinate the highest possible quality of care for patients. 